\title{
Evaluation of laryngoscopic view, intubation difficulty and sympathetic response during direct laryngoscopy in sniffing position versus simple head extension: a clinical comparative study
}

\author{
Chauhan $S^{1}$, Shende $S^{2}$, Shidhaye $\mathbf{R V}^{3}$ \\ ${ }^{1}$ Dr. Sangeeta Chauhan, Senior Resident, ${ }^{2}$ Dr. Seema Shende, Assistant Professor, ${ }^{3}$ Dr. Ramchandra Vinayak Shidhaye, \\ Professor, all authors are affiliated with Department of Anesthesiology and Critical Care, L.N. Medical College and J.K. \\ Hospital, Kolar Road Bhopal, MP, INDIA.
}

Address for Correspondence: Dr Seema Shende, Assistant Professor, Department of Anesthesiology and Critical Care, L.N. Medical College and J.K. Hospital, Kolar Road Bhopal, INDIA. Email: drseema26@gmail.com

\begin{abstract}
Background: Proper position of the head and the neck is important for optimizing laryngoscopic view and for ease of endotracheal intubation.We compared two different positions, sniffing position and simple head extension during direct laryngoscopy on the basis of laryngoscopic view, intubation difficulty and sympathetic response. Methodology: One hundred twenty patients of age group 20-50 years, scheduled for elective surgeries under general anaesthesia were divided into two equal groups in a randomized fashion. In group A $(n=60)$, sniffing position during laryngoscopy and intubation; and in group $\mathrm{B}(\mathrm{n}=60)$, simple head extension position during laryngoscopy and intubation. Laryngoscopy view, ease of intubation and hemodynamic parameters were recorded. Results: Demographic data and the different parameters for assessment of difficult airway were similar in both groups. Glottic visualization grade was superior in group A and intubation difficulty score were higher in Group B $(\mathrm{P}<0.05)$, Hemodynamic parameters at different time intervals were comparable. Conclusion: Sniffing position during laryngoscopy was found to be superior to simple head extention position in respect of better glottis visualization and ease of intubation though no difference in sympathetic response to intubation was found.
\end{abstract}

Keywords: Sniffing position, Simple head extention position, Direct laryngoscopic, Endotracheal intubation.

\section{Introduction}

Direct laryngoscopy is the mainstay of airway management. Proper position of the head and the neck is important for optimizing the laryngeal view during direct laryngoscopy. The importance of proper head and neck position for optimizing laryngeal view during laryngoscopy has been recognized since the procedure was first described by Kirstein in 1895.Inadequate positioning may result in prolonged or failed tracheal intubation attempts because of the inability to visualize the larynx. The sniffing position has been traditionally recommended for a long time as the optimal position for direct laryngoscopy, in this position, the neck must be flexed on the chest by elevating the head with a cushion or wooden block under the occipital and extending the

Manuscript received $29^{\text {th }}$ July 2016

Reviewed: $10^{\text {th }}$ August 2016

Author Corrected: $20^{\text {th }}$ August 2016

Accepted for Publication $31^{\text {st }}$ August 2016 head at the atlanto-occipital joint. Direct laryngoscopy can also be performed with the head in simple extension i.e flexion of the neck on chest is avoided.Advocates of the sniffing position maintain that it aligns the oral,pharyngeal and laryngeal axes, allowing the line of vision to fall directly on the laryngeal inlet [1]. Concerns about the anatomical soundness of the Three Axes Alignment Theory (TAAT) [2] were raised however during the last decade. Subsequently, the superiority of the sniffing position over other head and neck positions was also questioned. Futhermore, it was found that elevating the head higher than what is needed for a conventional sniffing position may improve laryngeal exposure in some patients. The paucity of clinical research that attempted to investigate the optimal head position for direct laryngoscopy is surprising, considering the frequency with which the 
technique is performed and the complications that may result from difficult laryngeal visualization. This study was carried out to evaluate the laryngoscopic view in sniffing position compared with the simple head extension during direct laryngoscopy in elective surgeries. We also evaluated the intubating conditions obtained with the two positions. The complexity of intubation was assessed by using a quantitative score "The Intubation Difficulty Score" The predictive factors associated with improvement of glottic visualization by the sniffing position maneuver were also studied.We also studied sympathetic response to intubation in sniffing position and simple head extension.

\section{Methodology}

After Institutional ethics committee approval, 120 American society of anaesthesiologists (ASA) grade I and II patients of age group between 20 to 50 years and of both genders, modified mallampati class I and II , scheduled for elective surgery under general anaesthesia with tracheal intubation were included in the study after their informed written consent. Patients having BMI $>30 \mathrm{Kg} / \mathrm{m}^{2}$, propofol or other drugs allergy, bucked teeth, restricted neck movements, interincisor gap $<2.5$ $\mathrm{cm}$, pharyngeal pathology, history of hiatus hernia, gastro oesophageal reflux, cervical spondylosis, hypertention, diabetes, bleeding disorder and patients on antiplatelet or anticoagulant drugs and pregnant females were excluded from the study.

Patients were randomly distributed in two equal groups. Group A: Sniffing position group.

Group B: Simple head extention group.

Method of randomization of patients was block randomization. Subjects were allocated to two groups: Group A and Group B Of 60 patients each $(n=60)$. Total 30 Blocks of size 4 each with treatment allocation of 1:1 for Group A and Group B were created with the help of computer software. Coded opaque sealed envelopes (total 30) were used; each envelope was used for four patients leading to random assignment of one subject to one group.

Preoperative airway assessment was done. Mouth opening was measured by asking the patients to open the mouth as wide as possible and interincisor gap (in $\mathrm{cm})$ in the midline was measured.value $<3.5 \mathrm{~cm}$ was considered predictive of intubation difficulty.Thyromental distance was measured along a straight from the thyroid notch to the lower border of the mandibular mentum with the head in full extension .A value $<6.5 \mathrm{cms}$ was considered associated with difficult intubation. Sternomental distance was measured along a straight line from the mentum to the sternal notch with the head in full extension.A value $<12.5 \mathrm{cms}$ was considered associated with difficult intubation. Protrusion of mandible:Patients were asked to prognath, with mandible subluxation graded as positive if the patient could bring the lower incisors forwards in front of the upper incisors,as none if the lower incisor and the upper incisor were tip to tip, and as negative if the patients was unable to perform these manuevres. The amplitude of neck and head movement was measured as described by Wilson and colleagues [3]. subject fully extends the head and neck,a pencil is placed flat on the forehead and the patients is asked to fully flex while the observer measures the change of angle in reference to a fixed point.This is then divided into $<80^{\circ} \&>80^{\circ}$.

Modified Mallampati Classification [4]: The patient was seated in the front of the observer with the head in neutral position, mouth wide open and maximum protrusion of the tongue without phonation.The visibility of oropharyngeal structures were classified as:

Class I: Visualization of the soft palate, fauces, uvula, anterior and posterior pillars.

Class II: Visualization of the soft palate, fauces and the base of uvula.

Class III: Visualization of the soft palate, and the base of uvula.

Class IV: Visualization of the hard palate only.

Patients were kept nil per oral for eight hours prior to the surgery.All patients were premedicated with inj glycopyrrolate $0.005 \mathrm{mg} / \mathrm{kg}$ iv. After arrival in the operation room noninvasive monitoring devices (noninvasive blood pressure, electrocardiograph leads and pulse oxymeter) were attached (Schillers Truscope II Monitor), after securing the intravenous line. Before the induction of anaesthesia all the Group A (Sniffing position) patients were placed supine and a cushioned wooden block of $8 \mathrm{~cm}$ height was placed under the head. At the time of laryngoscopy, the head was extended on the atlanto; occipitaljoint maximally.GroupB (simple head extension) patients were placed supine without the wooden block. The head was extended maximally on the atlanto occipital joint at the time of laryngoscopy. 
Following preoxygenation for 5 minutes, the standard induction technique was applied to all the patient which included midazolam $0.05 \mathrm{mg} / \mathrm{kg}$, fentanyl $2 \mu \mathrm{g} / \mathrm{kg}$ and propofol $2 \mathrm{mg} / \mathrm{kg}$.Neuromuscular block included $1.5 \mathrm{mg} / \mathrm{kg}$ of succinylcholine, after ventilation with oxygen for one minute.

We did laryngoscopy in all the patients using threesized Macintosh laryngoscope blade to ensure the consistency of the technique. Glottic visualization during laryngoscopy was assessed using modified Cormack and Lehane classification [5] (without optimal laryngeal manipulation). External laryngeal manipulation was permitted after evaluation in order to facilitate endotracheal intubation. After assessing the grade of laryngoscopy, tracheal intubation was performed and intubation difficulty score [6] was used to asses difficulty in intubation.

Intubation difficulty score (IDS):

$\mathrm{N}_{1}$ 0-No supplementary attempt required

1-Any supplementary attempt required

$\mathrm{N}_{2}$ 0-No supplementary operator required

1-Any supplementary operator required

$\mathrm{N}_{3}$ 0-No alternative intubation technique used

1-Any alternative intubation technique used

$\mathrm{N}_{4} 0$ - Cormack and Lehane Grade 1

1-Cormack and Lehane Grade 2

2-Cormack and Lehane Grade 3

3-Cormack and Lehane Grade 4

$\mathrm{N}_{5}$ 0-No subjectively increased lifting force required during laryngoscopy.
1-Subjectively increased lifting force required during laryngoscopy. $\mathrm{N}_{6}$ 0-No optimal external laryngeal manipulation required.

1-Optimal external laryngeal manipulation required

$\mathrm{N}_{7} 0$-Vocal cords are abducted

1 -Vocal cords are adducted

IDS is the sum of $\mathrm{N}_{1}$ to $\mathrm{N}_{7}$

Score $0=$ no difficulty at all.

Score $1-5=$ mild difficulty.

Score $>5=$ moderate to severe difficulty

Sympathetic stimulation in terms of heart rate and mean blood pressure was noted 5 min before administration of propofol, at the time of laryngoscopy and $10 \mathrm{~min}$ after laryngoscopy.

Rest of anaesthesia was continued as per standard protocol.Anaesthesia was maintained with $\mathrm{O}_{2}, \mathrm{~N}_{2} \mathrm{O}$, isoflurane and muscle relaxant used was atracurium. At the end of procedure residual neuromuscular blocker was reversed with neostigmine and glycopyrrolate. All the patients were extubated and shifted to post anaesthesia care unit, complication like fall in oxygen saturation and dysrrhythmias during laryngoscopy were also recorded. Statistical analysis was done using SPSS version 16. : All the Quantitative data was presented as mean and standard deviation and compared using student's t-test. Qualitative data such as modified mallampati grade, glottis visualization grade and intubation difficulty score were analysed using chisquare test. P-value of $<0.05$ was considered as significant.

\section{Result}

Both the groups were comparable in terms of age,sex,ASA Grade and BMI.There was no significant difference between the two groups.(P value $>0.05)$ as per table 1.Both the groups were comparable in terms of Modified Mallampatti Classification, interincisor gap, hyomental distance, thyromental distance and sternomental distance. $(\mathrm{P}$ vaule $>0.05)($ table 2). Comparison of intubation difficulty score between two groups demonstrated no significant differences (table 3) except in $\mathrm{N}_{3}$ which implies alternative technique for intubation and $\mathrm{N}_{4}$ which implies the laryngoscopic view.More patients in GroupB had $N_{3}$ score of one $(n=31)$ as compared to $\operatorname{GroupA}(n=16)(\mathrm{p}<0.05)$.

\section{Table-1: Demographic Parameters}

\begin{tabular}{|l|l|l|}
\hline PARAMETERS & $\begin{array}{l}\text { GROUP A(N=60) } \\
\text { Mean } \pm \text { SD }\end{array}$ & $\begin{array}{l}\text { GROUP B(N=60) } \\
\text { Mean } \pm \text { SD }\end{array}$ \\
\hline Age $(\mathrm{yrs})$ & $31.28 \pm 8.04$ & $30.90 \pm 6.89^{*}$ \\
\hline Sex $(\mathrm{m}: \mathrm{f})$ & $31: 29$ & $32: 28^{*}$ \\
\hline BMI $\left(\mathrm{Kg} / \mathrm{m}^{2}\right)$ & $22.87 \pm 2.49$ & $23.73 \pm 3.02^{*}$ \\
\hline
\end{tabular}

$*$ p-value $>0.05 * *$ p-value significant at $0.05 ; * * *$ p-value significant at 0.005 
Table-2: Predictors of Difficult Intubation

\begin{tabular}{|l|l|l|}
\hline Predictors of difficult intubation & $\begin{array}{l}\text { Group A(N=60) } \\
\text { Mean } \pm \text { SD }\end{array}$ & $\begin{array}{l}\text { Group B(N=60) } \\
\text { Mean } \pm \text { SD }\end{array}$ \\
\hline Interincisor Gap & $60.90 \pm 2.04$ & $60.36 \pm 2.19^{*}$ \\
\hline Hyomental Distance & $55.18 \pm 3.21$ & $55.36 \pm 3.70^{*}$ \\
\hline Thyromental Distance & $84.96 \pm 2.68$ & $84.55 \pm 3.02^{*}$ \\
\hline Sternomental Distance & $165.56 \pm 4.95$ & $165.23 \pm 5.11^{*}$ \\
\hline $\begin{array}{l}\text { Mallampati Grade } \\
\text { GradeI : Grade II }\end{array}$ & $52: 08$ & $46: 14^{*}$ \\
\hline
\end{tabular}

$*$ p-value $>0.05 * *$ p-value significant at $0.05 ; * * *$ p-value significant at 0.005

Table-3: Intubation Difficulty Score

\begin{tabular}{|c|c|c|c|c|c|}
\hline \multicolumn{2}{|c|}{ Parameters Deciding intubation difficulty Score } & \multirow[b]{2}{*}{0} & \multirow{2}{*}{$\begin{array}{l}\text { Group } \\
\mathbf{A}(\mathbf{N}=\mathbf{6 0}) \\
60\end{array}$} & \multicolumn{2}{|c|}{ Group $B(N=60)$} \\
\hline \multirow[t]{2}{*}{$\mathrm{N}_{1}$} & \multirow[t]{2}{*}{ Requirement of supplementary attempt } & & & 58 & \multirow[t]{2}{*}{$*$} \\
\hline & & 1 & 00 & 02 & \\
\hline \multirow[t]{2}{*}{$\mathrm{N}_{2}$} & \multirow[t]{2}{*}{ Requirement of supplementary operator } & 0 & 59 & 56 & \multirow[t]{2}{*}{$*$} \\
\hline & & 1 & 01 & 04 & \\
\hline \multirow[t]{2}{*}{$\mathrm{N}_{3}$} & \multirow[t]{2}{*}{ Requirement of alternative technique } & 0 & 44 & 29 & \multirow[t]{2}{*}{$* * *$} \\
\hline & & 1 & 16 & 31 & \\
\hline \multirow[t]{4}{*}{$\mathrm{N}_{4}$} & Cormack and Lehane Grade 1 & 0 & 50 & 38 & \multirow[t]{4}{*}{$* *$} \\
\hline & Cormack and Lehane Grade 2 & 1 & 08 & 18 & \\
\hline & Cormack and Lehane Grade 3 & 2 & 02 & 04 & \\
\hline & Cormack and Lehane Grade 4 & 3 & 00 & 00 & \\
\hline \multirow[t]{2}{*}{$\mathrm{N}_{5}$} & \multirow{2}{*}{$\begin{array}{l}\text { Requirement of increased lifting force during } \\
\text { laryngoscopy }\end{array}$} & 0 & 49 & 40 & \multirow[t]{2}{*}{$*$} \\
\hline & & 1 & 11 & 20 & \\
\hline \multirow[t]{2}{*}{$\mathrm{N}_{6}$} & \multirow[t]{2}{*}{ Requirement of optimal external manipulation } & 0 & 35 & 27 & \multirow[t]{2}{*}{$*$} \\
\hline & & 1 & 25 & 33 & \\
\hline \multirow[t]{2}{*}{$\mathrm{N}_{7}$} & \multirow[t]{2}{*}{ Vocal Cord Position } & 0 & 59 & 60 & \multirow[t]{2}{*}{$*$} \\
\hline & & 1 & 01 & 00 & \\
\hline
\end{tabular}

$*$ p-value $>0.05 * *$ p-value significant at $0.05 ; * * *$ p-value significant at 0.005

Table-4: Laryngoscopic View and Intubation Difficulty

\begin{tabular}{|c|c|c|c|c|}
\hline \multicolumn{2}{|l|}{ CL Grade \& IDS } & \multirow{2}{*}{$\begin{array}{l}\text { Group } A(n=60) \\
50\end{array}$} & \multicolumn{2}{|c|}{ Group B(n=60) } \\
\hline \multirow{4}{*}{$\begin{array}{l}\text { Cormack And Lehane } \\
\text { grade }\end{array}$} & GradeI & & 38 & \multirow[t]{4}{*}{$* *$} \\
\hline & GradeII & 08 & 18 & \\
\hline & GradeIII & 02 & 04 & \\
\hline & GradeIV & 00 & 00 & \\
\hline \multirow{3}{*}{$\begin{array}{l}\text { Intubation Difficulty } \\
\text { Score }\end{array}$} & 0 & 38 & \multicolumn{2}{|l|}{$28 * *$} \\
\hline & $1-5$ & 13 & \multicolumn{2}{|l|}{$18 * *$} \\
\hline & $>5$ & 09 & \multicolumn{2}{|l|}{$14^{*}$} \\
\hline
\end{tabular}

$*$ p-value $>0.05 * *$ p-value significant at $0.05 ; * * *$ p-value significant at 0.005

Similarly, there were fewer patients in Group B $(n=29)$ than Group A $(n=44)$ with $\mathrm{N}_{3}$ score of zero $(\mathrm{p}<0.05)$. The P value was 0.005 for $\mathrm{N}_{3}$ variable in two groups which was highly significant. Laryngoscopic view was better in group A with more patients having a $\mathrm{N}$ score of zero $(n=50)$ as compared to group $B(n=38)$. similarly there were more patients in 
group B ( $n=18)$ as compared to group A $(n=8)$ with $N$ score of one.Also, more patients in group B ( $n=4)$ had N score of two as compared to group $\mathrm{A}(\mathrm{n}=2)$. no patients in either group had $\mathrm{N}$ score of three. The total intubation difficulty score determining the ease of tracheal intubation was superior in group $\mathrm{A}$ than in group $\mathrm{B}(\mathrm{P}=0.04)$. Glottic visualization grade was superior in-group A as compared to Group B (table 4). There were no statistically significant difference in mean heart rate and mean arterial blood pressure in both the groups (table 5).

Table-5: Hemodynamics parameters

\begin{tabular}{|l|l|l|l|}
\hline \multicolumn{2}{|l|}{ Hemodynamics parameters } & $\begin{array}{l}\text { Group A(n=60) } \\
\text { Mean } \pm \text { SD }\end{array}$ & $\begin{array}{l}\text { Group B(n=60) } \\
\text { Mean } \pm \text { SD }\end{array}$ \\
\hline \multirow{3}{*}{$\mathrm{H} \mathrm{R}(/ \mathrm{min})$} & 5 min prior to propofol administration & $89.66 \pm 6.85$ & $88.96 \pm 6.44^{*}$ \\
\cline { 2 - 4 } & At the time of laryngoscopy & $106.48 \pm 7.90$ & $106.61 \pm 8.55^{*}$ \\
\cline { 2 - 4 } & 5 min after laryngoscopy & $100.68 \pm 7.54$ & $99.93 \pm 8.30^{*}$ \\
\cline { 2 - 4 } & 10 min after laryngoscopy & $94.38 \pm 6.51$ & $93.95 \pm 7.26^{*}$ \\
\hline \multirow{3}{*}{$\mathrm{MAP}(\mathrm{mmHg})$} & 5 min prior to propofol administration & $95.36 \pm 6.55$ & $96.23 \pm 5.26^{*}$ \\
\cline { 2 - 4 } & At the time of laryngoscopy & $107.10 \pm 5.91$ & $107.90 \pm 6.06^{*}$ \\
\cline { 2 - 4 } & 5 min after laryngoscopy & $103.38 \pm 5.67$ & $103.80 \pm 5.07^{*}$ \\
\cline { 2 - 4 } & 10 min after laryngoscopy & $98.83 \pm 5.57$ & $99.56 \pm 5.06^{*}$ \\
\hline
\end{tabular}

$*$ p-value $>0.05 * *$ p-value significant at $0.05 ; * * *$ p-value significant at 0.005

\section{Discussion}

Intubation difficulty is commonly identified as a risk factor for morbidity and mortility.Caplan et al. [7]. Difficult tracheal intubation is defined by the American society of anaesthesiology [8] as when proper insertion of the endotracheal tube by convention laryngoscopy requires more than three attempts or more than ten minutes. The sniffing position is universally recommended for oro-tracheal intubation in the operating room Samsoon Gillespie et al[9] provided the first analysis of anatomical factors involved in laryngoscopy. According to him, the solution to the ease of intubation was to attain adequate depth of anesthesia and muscle relaxation.

Convention laryngoscopy and intubation requires a direct view of structures of larynx.Jackson [10] was first to emphasize the importance of position of head for laryngoscopy and intubation. The classical rationale for sniffing position is that the alignment of the mandibular axis, pharyngeal axis and laryngeal axis is facilitated, permitting successful direct laryngoscopy. The article by Banister and Macbeth [2] in 1944 is the only published experimental study to our knowledge that has attempted to provide an anatomical explanation and justification for use of this position. Adnet et al [11] using magnetic resonance imaging found that it is not possible to achieve anatomic alignment of the laryngeal, pharyngeal and the mouth axes in neutral, simple head extension and in sniffing position, however the angle between the line of vision and the laryngeal axis decreased in both simple head extension and the sniffing position compared with the neutral position. In addition the sum of the angle between pharyngeal axis and the laryngeal axis and that between mouth axis and the pharyngeal axis was least in the sniffing position suggesting an advantage of the sniffing position over the simple head extension position. This study involved non anaesthetized volunteers and the laryngoscope blade was not used.Chow HC [12] further investigated the concepts of three axes and concluded that there is only involvement of two axes "oral and pharyngeal" and "the tongue". All these studies however pointed out that the angle between laryngeal axis and the line of vision was detected in sniffing as well as simple head extension position.

Thus these positions are comparable among themselves but better than neutral position .Our study was done to validate the benefit of the systemic use of sniffing position as compared to simple head extension position for patients undergoing elective surgeries under general anaesthesia with endotracheal intubation. In our study both groups did not differ demographically .Parameters of airway assessment and Mallampati grade were comparable in both the groups. The blade size was standardized for consistency.Our finding correlates well with the study by Singhal et al [13], they found intubation difficulty score was better in patients with 
sniffing position as compared to simple head extension position. They found that both the groups were comparable as regard to seven variables of intubation difficulty score except for N3 variable which included alternative intubation techniques like change of position,change of blade or use of stylet. They did not note any statistical difference in N4 variable, contrary to this we found statistical significant difference in glottis visualization grade N4 in both the groups, with N4 being better in sniffing position. Adnet $\mathrm{F}$ et al[14] found no significant advantage of the sniffing position over simple head extension in terms of laryngoscopic view.On the contrary of this, we found better glottis visualization in sniffing position as compared to simple head extension position.

Bhattarai B et al[15] found clinically better glottis visualization in sniffing position but statistically not significant with simple head extension position when compared during direct laryngoscopy, but the intubation difficulty score was statistically significant in sniffing position as compared to simple head extension position. Ambardekar $M$ et al [16] also noted that the use of sniffing position for direct laryngoscopy was associated with an improvement in laryngoscopic view.

The results of our study are supported by the studies of Adnet et al, Bhattarai B et al, Ambardekar $\mathrm{M}$ et al, Singhal et al $[13,14,15,16]$ in terms of intubation difficulty score in two groups. All these studies suggest that sniffing position offers more ease of tracheal intubation and better laryngoscopic view as compared to simple head extension position in difficult intubation situations like long standing diabetes mellitus, sleep apnea, loose upper incisors and tumors of the airway ect. In our study, we excluded these patient and found better laryngoscopic view in sniffing position in normal patients as well.

We also evaluated the sympathetic response to laryngoscopy in both positions expecting favorable response with sniffing position reflected by better hemodynamic parameters. In sniffing position glottis visualization as well as ease of intubation is better as compared to simple head extension position needing less manipulation required for glottis view and intubation and thus reducing the sympathetic response. But we failed to find such difference and both the groups were found to be comparable regarding hemodynamic parameters.

\section{Conclusion}

Sniffing position during laryngoscopy was found to be superior to simple head extention position in respect of better glottis visualization and ease of intubation .though no difference in sympathetic response to intubation was found.

Funding: Nil, Conflict of interest: None initiated, Permission from IRB: Yes

\section{References}

1. Stoelting RK: Endotracheal intubation, Anesthesia. Edited by Miller RD. New York, Churchill Livingstone, 1986, pp 523-32.

2. Bannister F, Macbeth R. Direct laryngoscopy and tracheal intubation. The Lancet. 1944 Nov 18;244(6325):651-4.

3. Wilson ME, Spiegelhalter D, Robertson JA, Lesser P. Predicting difficult intubation. British Journal of Anaesthesia. 1988 Aug 1;61(2):211-6.

4. Mallampati SR, Gugino LD, Desai SP, Waraksa B, Freiberger D, Liu PL: A clinical sign to predict difficult intubation: A prospective study. Can Anaesth Soc J. 1985 Jul;32(4):429-34.

5. Cormack RS, Lehane J. Difficult tracheal intubation in obstetrics. Anaesthesia. 1984 Nov 1;39(11):1105-11.

6. Adnet F, Borron SW, Racine SX, Clemessy JL, Fournier JL, Plaisance P, Lapandry C. The intubation difficulty scale (IDS) proposal and evaluation of a new score characterizing the complexity of endotracheal intubation. The Journal of the American Society of Anesthesiologists. 1997 Dec 1;87(6):1290-7.

7. Caplan RA, Posner KL, Ward RJ, Cheney FW. Adverse respiratory events in anesthesia: a closed claims analysis. Anesthesiology. 1990 May;72(5):82833.

8. American Society of Anesthesiologists Task Force on Management of the Difficult Airway. Practice guidelines for management of the difficult airway. Anesthesiology. 1993;78:597-602.

9. Samsoon GL, Young JR. Difficult tracheal intubation: a retrospective study. Anaesthesia. 1987 May 1;42(5):487-90. 
10. Jackson $\mathrm{C}$ :The technique of insertion of intratracheal insufflation tubes.Surg Gynecol Obstet 1913;17:507-9.

11. Adnet F, Borron SW, Dumas JL, Lapostolle F, Cupa M, Lapandry C. Study of the "sniffing position" by magnetic resonance imaging. The Journal of the American Society of Anesthesiologists. 2001 Jan 1;94(1):83-6.

12. Chou HC, Wu TL. Rethinking the three axes alignment theory for direct laryngoscopy. Acta Anaesthesiologica Scandinavica. 2001 Feb 1;45(2):2612 ..

13. Singhal SK, Malhotra N, Sharma S. Comparison of sniffing position and simple head extension for visualization of glottis during direct laryngoscopy. Indian Journal of Anaesthesia. 2008 Sep 1;52(5):546.
14. Adnet F, Baillard C, Borron SW, Denantes C, Lefebvre L, Galinski M, Martinez C, Cupa M, Lapostolle F. Randomized study comparing the "sniffing position" with simple head extension for laryngoscopic view in elective surgery patients. The Journal of the American Society of Anesthesiologists. 2001 Oct 1;95(4):836-41.

15. Bhattarai B, Shrestha SK, Kandel S. Comparison of sniffing position and simple head extension for visualization of glottis during direct laryngoscopy. Kathmandu University Medical Journal. 2012 Jun 7;9(1):58-63.

16. Ambardekar M, Pandya S, Ahuja P. Comparison of the sniffing position with simple head extension for laryngoscopic view in elective surgical patients. Internet J Anesthesiol. 2008;17:15.

\section{How to cite this article?}

Chauhan S, Shende S, Shidhaye RV. Evaluation of laryngoscopic view, intubation difficulty and sympathetic response during direct laryngoscopy in sniffing position versus simple head extension: a clinical comparative study. Int J Med Res Rev 2016;4(9):1531-1537.doi:10.17511/ijmrr.2016.i09.03. 